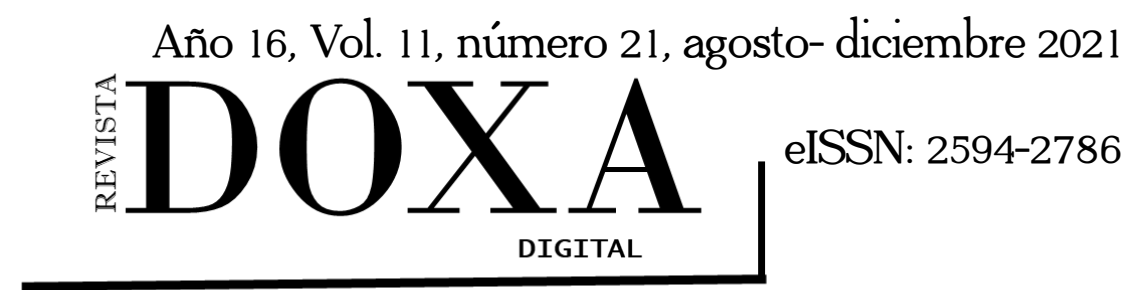

Sección: Ciencias Sociales

Recibido: Marzo 2021

Aceptado: Junio 2021

DOI: $10.52191 /$ rdojs.2021.201

Pág.: 52-71

\title{
Una mirada socioambiental y territorial de la pandemia
}

\section{A socio-environmental and territorial vision of the pandemic}

Beatriz Ensabella*

\section{RESUMEN}

Presentamos un ensayo sobre el contexto de producción del Covid 19 y su relación con el capitalismo financiero. Para ello, acudimos a multiplicidad de fuentes y disciplinas como la epidemiología histórica, la historia social de la salud y la enfermedad, la historia ambiental, la ecoepidemiología o epidemiología ambiental, aunque siempre prevalece una perspectiva espacial, encuadrada en la geografía social crítica. Ponemos énfasis en múltiples escalas espaciales que interactúan, para llegar a conjugarlas en la escala local. Así, el ensayo comienza con planteos generales y de escala macro, para llegar al comportamiento territorial de la pandemia en la Argentina, sin profundizar en el caso.

PALABRAS CLAVE: epidemiología ambiental, pandemia en Argentina, barrios populares, riesgo, vulnerabilidad

\section{ABSTRACT}

We present an essay on the production context of Covid 19 and its relationship to financial capitalism. For this, we resort to a multiplicity of sources and disciplines such as historical epidemiology, social history of health and disease, environmental history, ecoepidemiology or environmental epidemiology, although a spatial perspective always prevails, framed in critical social geography. We emphasize multiple interacting spatial scales, to combine them at the local scale. Thus, the essay begins with general and macro-scale proposals, to arrive at the territorial behavior of the pandemic in Argentina, without delving into the case.

KEY WORDS: environmental epidemiology, pandemic in Argentina, popular neighborhoods, risk, vulnerability

*Profesora Asistente (encargada de trabajos prácticos) en Geografia Rural y Metodología de la Investigación. Departamento de Geografia, Facultad de Filosofia y Humanidades, Universidad Nacional de Córdoba. Investigadora de la Secretaría de Ciencia y Técnica de la UNC, sobre cuencas hídricas, problemáticas ambientales, investigaciuón cualitativa.. Contacto: bettyensabella@gmail.com 
Año 16, Vol. 11, número 21, agosto-diciembre

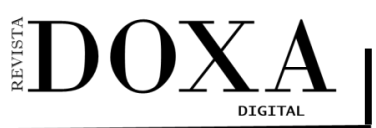

pISSN: 2395-8758 eISSN: 2594-2786
Sección: Ciencias Sociales

DOI: $10.52191 /$ rdojs.2021.201

pág.: 52-71
Beatriz Ensabella

Una mirada socioambiental ...

\section{Introducción}

Cuando comenzó a expandirse el coronavirus, y antes que se decreten las cuarentenas/ confinamientos en la mayor parte del mundo, asistíamos a un mundo convulsionado, con protestas en las calles, como Hong Kong, Santiago de Chile, Teherán, Bagdad, Beirut, París, Barcelona, Quito, Bogotá. Y se fueron apagando una a una, ya casi se habían borrado de nuestra memoria, pero no de la memoria histórica y a medida que se fue flexibilizando el confinamiento, fueron resurgiendo esas manifestaciones callejeras. Como sea, con una alta dosis de ingenio, durante las olas de protestas en Santiago, alguien proyectó una frase poderosa en un edificio: "No volveremos a la normalidad, porque la normalidad era el problema". Y a pesar de los esfuerzos, la pandemia ${ }^{1}$ continúa y parece imposible imaginar volver al "mundo antiguo", ese mundo que nos dejó tan indefensxs ante la llegada del virus letal.

También es cierto que ese mundo, tristemente, llevaba en alza los números de muertes de activistas sociales, de defensores ambientales, de feminicidios ${ }^{2}$. Un mundo o una sociedad global azotada por la ideología del no valor a la vida humana. Esta hipótesis desarrolló Williams Robinson en el Congreso de Fronteras de Ciudad Juárez, en octubre de 2015 y quedamos impactadxs por las cifras de armamentos, comercio de productos tóxicos, estadísticas de muertos y desapareci$\operatorname{dos}^{3}$. También impacta cuando tan claramente lo expresa Enrique Leff ${ }^{4}$ :

Terrorismo, secuestros, desapariciones, la indefensión de la gente y la impunidad que impera rebasa el límite de la criminalización de los líderes indígenas y campesinos porque lo que se está contraponiendo son los derechos de existencia de la gente, de los pueblos de la tierra, frente a la necesidad del capital de seguirse expandiendo. (Clacso TV, 30/09/2019).

1 La OMS advirtió al mundo de la letalidad del virus a principios de enero de 2020 y declaró emergencia pública el 30 del mismo mes; el 11 de marzo declaró la pandemia.

2 Según el informe de Global Witness, 212 personas defensoras de la tierra y el medio ambiente fueron asesinados durante el 2019. América Latina vuelve a ubicarse como la región más peligrosa para los defensores ambientales. Entre los países que registraron el mayor número de asesinatos se encuentran Colombia, Brasil, México, Honduras, Guatemala, Venezuela y Nicaragua. (Mongabay Latam, periodismo ambiental independiente, 29 de julio de 2020). La pandemia ha generado riesgos adicionales para mujeres víctimas-sobrevivientes de violencia de género, al estar confinadas con su agresor, se han incrementado los feminicidios.

3 Conferencia inaugural, XV Congreso Internacional sobre integración regional, fronteras y globalización en el continente americano y IV Congreso de Ciudades Fronterizas, 28, 29 y 30 de octubre de 2015, Universidad Autónoma de Ciudad Juárez, Chihuahua, México. Williams Robinson desarrolla parte de su pensamiento en Una teoría sobre el capitalismo global de 2013 y Producción, clase y Estado en un mundo transanacional de 2015, ambos editados por Siglo $\mathrm{XXI}$.

4 Entrevista de Karina Bidaseca para Clacso Tv, del 30 de setiembre de 2019. Pueden escucharla abriendo este enlace https://www.clacso.org/la-ecologia-politica-segun-enrique-leff/ 
Año 16, Vol. 11, número 21, agosto-diciembre

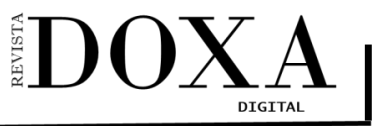

pISSN: 2395-8758 elSSN: 2594-2786
Sección: Ciencias Sociales

DOI: 10.52191/rdojs.2021.201

pág.: 52-71
Beatriz Ensabella

Una mirada socioambiental ...

Es real y la pandemia del Covid 19, deja expuesta la lógica del capitalismo financiero, tan agresiva con el planeta, que genera incertidumbre hacia el futuro, ¿existe un horizonte a mediano-largo plazo?, ¿hay futuro para la humanidad ${ }^{5}$ En esa inestabilidad en que está transcurriendo la existencia, el impacto del coronavirus es devastador para el Sur Global, donde las desigualdades, la pobreza, el desempleo, el hambre, amenazan de forma permanente la reproducción de la vida.

Pensamos que es necesario encuadrar este y todos los eventos epidemiológicos, en el contexto socio-económico, político de producción y desarrollo del evento y analizándolo en procesos de larga duración. Allí la geografía y las ciencias sociales en general, pueden analizar las claves para pensar y proponer otros mundos posibles, menos agresivos con los ecosistemas y que permitan una mejor salud física y psíquica para las sociedades. Nos interesa justamente, hacer ese análisis del contexto de producción del evento Covid 19. Para ello acudimos a multiplicidad de fuentes y disciplinas como la epidemiología histórica, la historia social de la salud y la enfermedad, la historia ambiental, la ecoepidemiología o epidemiología ambiental, aunque siempre prevalece una perspectiva espacial, encuadrada en la geografía social crítica. De allí es que el análisis pone énfasis en múltiples escalas espaciales, tratando de mirarlas en interacción, para llegar a conjugarlas en la escala local. Dicho esto, el ensayo comienza con planteos generales y de escala macro, para llegar al comportamiento territorial de la pandemia en la Argentina, sin ahondar en el caso.

Este ensayo que comparto, se compone de una serie de reflexiones que necesariamente requieren mayores análisis y profundizaciones, contrastando evidencias empíricas, datos estadísticos, cartografía específica, con una adecuada perspectiva teórica que permita traspasar la descripción, para llegar a realizar un enfoque problematizador, que invite a nuevas preguntas más que a proponer certezas.

\section{El evento Covid 19 o SARS-CoV-2 en su contexto de surgimiento y reproducción}

La irrupción del virus a escala planetaria, significó (aún lo sigue siendo), la movilización del campo científico para comprender más sobre el comportamiento del Covid 19, pero quizás existe un interrogante clave que nos inquieta y sigue latente, ¿por qué si los coronavirus ya circulaban e iban

\footnotetext{
5 El sociólogo y psicoanalista Rafael Sandoval (2020) de la Universidad de Guadalajara, México, advierte sobre esta cuestión en el sentido de que nos empujan hacia la des-movilización "No subestimemos que la insoportable conciencia de que somos mortales y cómo está siendo manipulada para generar procesos de desubjetivación para la perdida-desentido de la vida trascendente, a cambio de una forma de existencia "que se ilusiona con retardar la muerte al vivir lo que se puede vivir, ya que no hay posibilidades de vida digna" donde la cuestión es obstruir el despliegue de la autonomía singular y colectiva, la dignidad" (pág. 27).
} 
Año 16, Vol. 11, número 21, agosto-diciembre

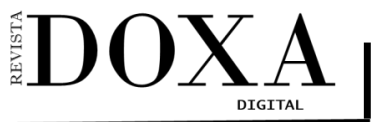

pISSN: 2395-8758 elSSN: 2594-2786
Sección: Ciencias Sociales

DOI: $10.52191 /$ rdojs.2021.201

pág.: 52-71
Beatriz Ensabella

Una mirada socioambiental ...

mutando, el Covid 19 se convirtió en una pandemia? ¿Qué relación tiene la pandemia del Covid 19 con el capitalismo en su fase financiera (si existe tal relación)? Varios sistemas sanitarios del mundo colapsaron, la situación económica es alarmante, un escenario mundial que va sumiendo a la humanidad en otra crisis profunda que se suma a las que el sistema viene transitando ${ }^{6}$ y que hace cada vez más difícil sostener a los Estados y sus poblaciones dado los pretendidos ajustes de parte de los organismos financieros internacionales.

Tratando de comenzar a buscar respuestas a nuestros interrogantes, en principio podemos argumentar que existe un amplio acuerdo entre los investigadores para reconocer que el virus ha surgido del mismo modo que otros anteriormente: saltando de un animal a los seres humanos... Murciélagos, pájaros y varios mamíferos (en particular los cerdos) albergan naturalmente múltiples coronavirus. En los humanos, hay siete tipos de coronavirus conocidos que pueden infectarnos. Cuatro de ellos causan diversas variedades de gripe común. $Y$ otros tres, de aparición reciente, producen trastornos mucho más graves y hasta letales, como el Síndrome Respiratorio Agudo (SARS-CoV-1), emergido en 2002-2003; el Síndrome Respiratorio de Oriente Medio (MERS), surgido en 2012; y por último esta nueva enfermedad, Covid 19, causada por el SARS-CoV-2, cuyo primer brote se detectó, en el mercado de mariscos de Wuhan en diciembre de 2019. Este nuevo germen tendría al murciélago como "huésped original" y a otro animal como "huésped intermedio" desde el cual, después de volverse particularmente peligroso, habría saltado a los humanos ${ }^{7}$.

Está comprobado que las migraciones de aves contribuyen a la propagación de virus. ("efecto mariposa"). Teoría de investigadores de la Universidad de Suwan, Corea del Sur, del campo de la bioingeniería, sostienen que existe relación entre las dinámicas ambientales globales y la presencia de nuevas pandemias. Están estudiando qué ocurre con los repositorios de nuevos virus en la An-

6 Las sucesivas crisis que enfrentamos (ecológica, financiera, ambiental, alimentaria, sanitaria) resultan del mismo fenómeno: un sistema que transforma todo - tierra, el agua, el aire que respiramos, los seres humanos- en mercancía, y no reconoce otro criterio que no sea la expansión de los negocios y la acumulación de ganancias. Se trata de una crisis de la civilización tal como fue hegemonizada por el sistema capitalista. Varios autores hablan de la crisis civilizatoria o crisis sistémica, por nombrar algunos Arturo Escobar, Eduardo Gudynas, Carlos Walter Porto-Gonçalves, Bernardo Manzano Fernández, Enrique Leef. Desde la ecología política estos autores defienden los derechos de la Naturaleza y de las luchas anti-sistémicas que brotan en múltiples localidades del mundo

7 Las cabezas del equipo de investigadores de China y del grupo de expertos internacionales Los enviados de la OMS para investigar los orígenes del virus ofrecieron un informe en febrero en Wuhan. Hasta ahora el resultado más contundente ha sido descartar como "extremadamente improbable" la teoría de que el patógeno pudo salir de un laboratorio situado en esta ciudad del centro de China. apuntan como hipótesis "más probable" a que el coronavirus llegó a las personas desde un "reservorio natural" tras pasar por una tercera especie. Sin embargo, no publicarán su informe preliminar en un contexto de crecientes tensiones entre Estados Unidos y China. "Un mero resumen no satisfaría la curiosidad de los lectores", dijo el jefe del equipo de investigadores, Peter Embarek a principios de marzo. Es evidente que se trata de una estrategia geopolítica. 
Año 16, Vol. 11, número 21, agosto-diciembre

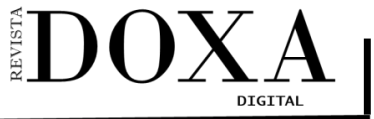

pISSN: 2395-8758 elSSN: 2594-2786
Sección: Ciencias Sociales

DOI: $10.52191 /$ rdojs.2021.201

pág.: 52-71
Beatriz Ensabella

Una mirada socioambiental ...

tártida y en las zonas polares del hemisferio norte. Sostienen que esos repositorios de aves en las zonas polares del hemisferio norte y sur, habían permanecido miles de años congelados, pero con el calentamiento global han comenzado a transitar, a movilizarse y ese fenómeno, lo asocian a complejos mecanismos efecto de los ciclos de manchas solares (cada 11 años, se activa las mutaciones de los virus y bacterias en los polos), producto de una mayor radiación ultravioleta. Si este dinamismo es así, los nuevos virus viajarían a través del krill que es consumido por las ballenas y los pingüinos, desde los cuales son transportados por aves migratorias. En suma, a medida en que se deshielan los casquetes polares, nuevos virus y bacterias están emergiendo y circulando, con lo cual es factible que lleguen a las grandes ciudades, a los centros poblacionales concentrados, que lleguen a los humanos. Esto es una teoría sin comprobación científica, pero lo destacamos por la estrecha relación de las enfermedades producidas por las mutaciones de coronavirus (en este caso el Covid 19), con los ecosistemas naturales y desde allí, con los seres vivos.

El grupo de virus más conocido, que es compartido por cerdos, aves y nosotros, está formado por diferentes cepas del virus de la gripe. Fue una gripe porcina o aviar la responsable de la gripe española de 1918, que probablemente comenzó en Houston (Texas) pero como los diarios españoles eran los únicos que publicaban los casos mortales de la enfermedad en el frente de batalla de la $1^{\circ}$ guerra mundial, se la asoció a ese país. Tardó ocho meses en difundirse por todo el mundo, a nuestro país llegó más tardíamente ${ }^{8}$. La mortífera gripe A (influenza H5N1 de 2005 y H1N1 de 2010 que ha causado 18.000 muertos), y sigue considerándose una gran amenaza, es una combinación de la gripe porcina y aviar. Se propaga a través de las aves y luego llega a la población humana a través de patos domesticados, aves de corral y granjas avícolas.

Las probabilidades de que los virus pasen de otras especies a los seres humanos aumentan si esas especies están en contacto estrecho con nosotros. Por lo tanto, la ganadería industrial así como los mercados de animales y aves vivas, proporcionan oportunidades para tales transmisiones, que son llamadas transmisiones zoonóticas. En este sentido, la Unión Internacional para la Conservación de la Naturaleza en su declaración sobre la pandemia de Covid 19 sostiene:

Los cambios en el uso de la tierra son un motor clave de las enfermedades zoonóticas emer- 
Año 16, Vol. 11, número 21, agosto-diciembre

DOXA
Sección: Ciencias Sociales

DOI: $10.52191 /$ rdojs.2021.201
Beatriz Ensabella

Una mirada socioambiental ...

pág.: 52-71

gentes. La deforestación, la fragmentación de los hábitats y la expansión de la frontera agrícola aumentan los contactos entre humanos y otros animales, aumentando potencialmente las posibilidades de que surjan y se propagan zoonosis (UICN, 14/04/2020, p.1).

Las zoonosis y la actual pandemia son expresiones de la degradación de los ecosistemas como consecuencia de la ruptura de los equilibrios en la biodiversidad. Debido a la deforestación, las grandes obras de infraestructura, la megaminería, los incendios, el avance de la agricultura y la ganadería industrial, muchas especies se han extinguido y otras han migrado a otros ecosistemas aumentando la interrelación con la especie humana e incrementando también las posibilidades de proliferación de virus desconocidos hasta el momento.

David Harvey plantea en relación con las respuestas de los Estados a la pandemia que:

Las autoridades públicas y los sistemas de atención de salud quedaron pronto saturados e insuficientes. Cuarenta años de neoliberalismo en América del Norte y del Sur y en Europa, han dejado lo público totalmente expuesto y mal preparado para enfrentar una crisis de salud pública de este tipo, a pesar de que los temores previos de SARS y Ébola proporcionaron abundantes advertencias y lecciones contundentes sobre qué era necesario hacer. En muchas partes del supuesto mundo "civilizado", los gobiernos locales y las autoridades regionales, que invariablemente forman la primera línea de defensa y seguridad en emergencias de salud pública, se vieron privadas de fondos como consecuencia de una política de austeridad diseñada para financiar recortes de impuestos y subsidios a las corporaciones y los ricos (Harvey, 2020, p. 4).

\section{La tríada sociedad, naturaleza, salud}

La invasión de los bosques y violación de la integridad de las especies está propagando nuevas enfermedades. En los últimos 50 años han surgido 300 nuevos patógenos a medida que destruimos el hábitat de las especies

y las manipulamos para obtener ganancias.

Vandana Shiva

El cambio climático global, el deterioro acelerado de la biodiversidad, la creciente desigualdad social y la concentración de la riqueza dentro y entre países, son todos síntomas de un mismo proceso subyacente, el modelo predominante de apropiación de la naturaleza y de relación al interior de las sociedades. 
Año 16, Vol. 11, número 21, agosto-diciembre

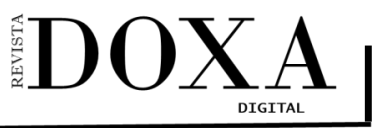

pISSN: 2395-8758 elSSN: 2594-2786
Sección: Ciencias Sociales

DOI: 10.52191/rdojs.2021.201
Beatriz Ensabella

Una mirada socioambiental ...

pág.: 52-71

Jason Moore, en su reciente publicación (2020) El capitalismo en la trama de la vida. Ecología y acumulación de capital ${ }^{9}$ explica lo que a su entender es la íntima relación entre capitalismo financiero y ecología-mundo. Sostiene que la ley del valor se expande por la ecología-mundo capitalista mediante tres revoluciones: 1) la transformación incesante del paisaje, 2) el incremento de la producción del trabajo, y 3) el aumento sin límites de técnicas de apropiación global de la naturaleza y esa forma de organización de la naturaleza mercantilizada, ha mercantilizado también la vida social y biológica. Estos argumentos los sustenta a través del visible y comprobable agotamiento de bienes naturales para hacer frente a las sucesivas crisis financieras. Se trata de un verdadero saqueo de bienes de la naturaleza, un modo extractivista de encarar el falso desarrollo de los pueblos, que justamente son los que terminan despojados de sus medios de vida. Las estrategias empleadas por gobiernos y empresas en ese contexto según Moore son, entre otras, horizontes de inversión cortos, que mitigan la administración ambiental a largo plazo porque dependen del mercado de valores; regulaciones ambientales laxas para atraer capitales de inversión que son depredadores ${ }^{10}$.

Con la pandemia, el debate sobre lo ambiental y la magnitud de los cambios en el sistema natural, constituye un tema de creciente importancia. A nadie se le escapa que crecimiento demográfico, degradación del mundo natural, desigualdades sociales, tienen estrecha relación con la salud pública. En efecto, el marcado deterioro de las condiciones de vida en amplios sectores poblacionales de todo el mundo, precisa de manera urgente una revisión de los términos en que se produce la interacción salud-ambiente. El interés se ubica en torno a problemas como el de las enfermedades infecciosas emergentes, también empiezan a manifestarse con respecto a otros riesgos de malestar, enfermedad y muerte que afloran. $Y$ nos invade como humanidad hace ya un tiempo, la duda sobre ¿cuáles son las consecuencias para la salud que se derivan de las interacciones entre el ambiente y el desarrollo en un mundo neoliberal?; ¿los efectos de ese intercambio sobre la salud son análogos en espacios diferenciados?; en un mundo desigual ¿cómo experimentan esas interacciones las sociedades opulentas y cómo las empobrecidas, los inmigrantes, los desplazados?

Es decir que tenemos que analizar la tríada sociedad (cultura) - salud/enfermedad- y ambiente

9 Moore acuñó el término Capitaloceno para referir al lugar central del capitalismo como fuerza transformadora de la ecología-mundo. El capitalismo supone un determinado tipo de "ecología mundial" que implica formas de producción y distribución de la riqueza, sistema de poder y ecosistemas hechos tanto de naturaleza humanas como extrahumanas. (posteo en Facebook de Patricia Pintos, 3 de setiembre de 2020, tomado de Traficante de sueños, la editorial del libro de Moore).

10 Un ejemplo es la financiarización de la contaminación mediante la mercantilización de bonos de Carbono. 
Año 16, Vol. 11, número 21, agosto-diciembre

DOXA
Sección: Ciencias Sociales

DOI: $10.52191 /$ rdojs.2021.201

pág.: 52-71
Beatriz Ensabella

Una mirada socioambiental ...

considerando la variable espacio-temporal de manera indisoluble.

Si consideramos la historia ambiental de la salud, veremos que tiene importantes antecedentes. Un texto a la vez clásico y temprano en este campo es el libro Plagas y Pueblos, del historiador norteamericano William H. McNeill, cuya primera edición data de 1976. Allí, el autor, se propone dejar al descubierto una dimensión de la historia que refiere a la de los encuentros de la humanidad con las enfermedades infecciosas y las consecuencias de largo alcance que se produjeron cada vez que los contactos a través de la frontera de una enfermedad distinta, permitieron que una infección invadiera una población carente de toda inmunidad contra el agente patógeno.

...no parece absurdo clasificar el papel ecológico de la humanidad, en su relación con otras formas de vida, como una enfermedad. Desde que el lenguaje permitió que la evolución cultural humana incidiera sobre procesos antiquísimos de evolución biológica, la humanidad ha estado en condiciones de alterar los más antiguos equilibrios de la naturaleza de la misma manera que la enfermedad altera el equilibrio natural en el cuerpo de un huésped... Desde el punto de vista de otros organismos, la humanidad se asemeja así a una grave enfermedad epidémica, cuyas recaídas ocasionales en formas de conducta menos virulentas nunca le han bastado para entablar una relación estable y crónica. (McNeill, 1976:21).

La historia ambiental aborda su objeto de estudio a partir de tres niveles de relación. El primero se refiere al mundo biofísico en el que transcurre la acción humana; el segundo, a las tecnologías involucradas en dicha acción, y a las relaciones sociales vinculadas a dichas tecnologías; el tercero, a la cultura, los valores y las normas que orientan tanto nuestras relaciones con el mundo natural, como las que caracterizan nuestra vida social. Este planteamiento metodológico facilita la construcción de un marco conceptual capaz de proporcionar las herramientas necesarias para la tarea de enfrentar la relación salud - ambiente - desarrollo en su doble dimensión de estructura (espacial) y proceso (temporal), incorporando los aportes de diversas disciplinas.

La importancia de la cultura queda reflejada en lo que sostiene McNeill sobre las enfermedades bacterianas y virales infecciosas que pasan directamente de un ser humano a otro sin huésped intermediario "vienen a ser (las enfermedades infecciosas) por excelencia, las enfermedades de la civilización: el rasgo peculiar y la carga epidemiológica de las ciudades y del campo que está en contacto con las ciudades" (McNeiil, 1976, p. 234).

\section{Los cambios ambientales y la salud}


Año 16, Vol. 11, número 21, agosto-diciembre

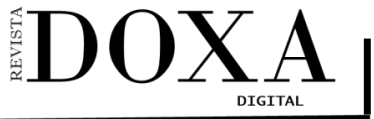

pISSN: 2395-8758 eISSN: 2594-2786
Sección: Ciencias Sociales

DOI: $10.52191 /$ rdojs.2021.201

pág.: 52-71
Beatriz Ensabella

Una mirada socioambiental ...

Hoy, un clima cada vez más inestable, la acelerada pérdida de especies y crecientes inequidades económicas, plantean un desafío a la tolerancia y la resistencia de los sistemas naturales. Actuando en conjunto, estos elementos de cambio contribuyen resurgimiento y redistribución de enfermedades infecciosas a escala global. Paul Epstein, 1997

Como nunca antes, afrontamos las consecuencias del impacto ambiental nocivo y acumulativo de los diferentes tipos de actividad humana con relación a la naturaleza y los ecosistemas, situación crítica que nos plantea, no solo retos en cuanto a la satisfacción de las necesidades básicas en el momento actual, sino también en términos definitivos de supervivencia de la especie. En este periodo histórico, capitaloceno según Moore, la epidemiología se convierte en una herramienta fundamental para el estudio de la relación entre salud y ambiente en las comunidades, posibilitando procesos de investigación aplicada, orientados a la identificación de factores de riesgo ambiental, elaboración de diagnósticos de salud poblacional, cuantificación del impacto sobre los ecosistemas y evaluación de intervenciones tendientes a controlar y reducir las secuelas.

El mundo globalizado es el resultado de largos periodos de comercio internacional que se comenzó en la Europa medieval, y que pasó por el descubrimiento de América y la industrialización hasta llegar a nuestros tiempos, pero durante todos estos años los productos y bienes no han sido los únicos que han logrado traspasar fronteras, así lo han hecho de igual forma las personas y las culturas. Las migraciones han traído consigo el conocimiento, la expansión de nuevas formas de pensamiento y el crecimiento de nuevas urbes superpobladas, que han sido el escenario propicio para la generación y propagación de enfermedades. El entorno en el que se encuentran las personas determina su estado de salud; ya Hipócrates, en el siglo V a. C., en su Tratado de los aires, las aguas y los lugares, discute las causas ambientales de las enfermedades, al sugerir que tales condiciones ayudaban a los médicos a evaluar y comprender el estado de salud de las comunidades.

Posteriormente, en 1854, John Snow lo demostraba con su estudio sobre el cólera en Londres. Fue el primero en hacer mapas de la epidemia (1854). Le permitió concluir que los casos estaban relacionadas con lugares específicos de provisión de agua, estableciendo así elementos definitivos para el desarrollo de la epidemiología, disciplina científica básica de la salud pública que aporta herramientas para el conocimiento del proceso salud-enfermedad de los distintos grupos humanos y orienta, de acuerdo con este conocimiento, las intervenciones que se requieren, además de brindar elementos para la evaluación y diagnóstico de los diferentes problemas a los que se enfrenta. 
Año 16, Vol. 11, número 21, agosto-diciembre

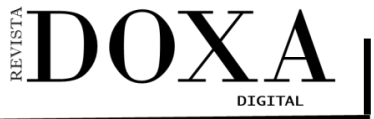

pISSN: 2395-8758 eISSN: 2594-2786
Sección: Ciencias Sociales

DOI: 10.52191/rdojs.2021.201

pág.: 52-71
Beatriz Ensabella

Una mirada socioambiental ...

(Montoya et al, 2009).

El problema ambiental se ha propagado mucho más por la intensificación del consumo que por el aumento poblacional. También es de vital importancia abordar el tema de las relaciones entre países con grandes diferencias en su crecimiento económico, pues este fenómeno establece el escenario propicio para la generación de desequilibrios económicos y comerciales que producen endeudamiento y menos peso en las negociaciones internacionales.

Acumulación de capital, desequilibrios urbano-rurales generados por los agentes del mercado, explosión de nuevos nichos de renta, reaparición de discursos discriminatorios hacia la población afrodescendiente y los pueblos originarios, desequilibrios hídricos efecto de los cambios ambientales globales, son algunos de los temas que deben abordarse para medir el riesgo y la exposición al contagio por infecciones; son variables importantes a la hora de analizar una pandemia como la del coronavirus (Hidalgo, Rodrigo et al, 2020, p. 5).

Como consecuencia de todo lo expuesto, aparece la dimensión de la vulnerabilidad social frente a los cambios ambientales, comprendida como la interfaz entre la exposición a amenazas físicas para el bienestar humano y la capacidad de las personas y comunidades para controlar tales amenazas. (Araujo Gonzáles, 2015). Vulnerabilidad que aunque es un problema que de una u otra forma nos impacta a todos, se encuentra enmarcada en un escenario de desigualdades, dadas las enormes brechas entre países ricos y pobres y al interior de los mismos, lo cual acentúa aún más la problemática y entorpece sus posibles soluciones. Pero remarcamos el anudamiento entre lo socioeconómico y lo ecológico, como sentencian Montoya et al (2009):

Para reducir este fenómeno, evitando que su propósito se circunscriba solo en la visión económica de la desigualdad, se requiere alcanzar un grado de conciencia fundamentado en la lógica de la naturaleza y el comportamiento ecológico centrado en la protección; por lo tanto, es esencial disminuir las necesidades ficticias (aquellas que provienen de la conciencia alienada y son producidas por la sociedad de consumo capitalista), y que están por fuera de las necesidades reales (las que provienen de la naturaleza misma del hombre) (p. 214).

En el mismo sentido Martínez Alier (2000), uno de los referentes de la ecología política, manifiesta:

El consumo de los ricos es lo que está llevando realmente a esta destrucción de la naturaleza, y a este abuso contra la gente pobre. Aunque nueve de cada diez niños nacen hoy en el sur, el niño que nace en el norte, estará destinado a consumir y contaminar como veintisiete niños del sur (p. 106). 
Año 16, Vol. 11, número 21, agosto-diciembre

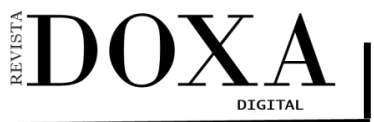
eISSN: 2594-2786
pISSN: 2395-8758
Sección: Ciencias Sociales

DOI: 10.52191/rdojs.2021.201
Beatriz Ensabella

Una mirada socioambiental ...

pág.: 52-71

La evolución del Covid 19 ha mostrado que la pandemia es una amenaza real que afecta a todo el mundo pero no de forma igual. Hay personas y colectivos que presentan vulnerabilidades específicas, por ejemplo los adultos mayores, la población migrante, las personas discapacitadas, las infancias, las mujeres, los afrodescencientes e indígenas y también las vulnerabilidades derivadas de un proceso económico desfavorable (las familias en asentamientos informales, la población que vive en la pobreza, las situaciones de precariedad laboral) exponen a estos grupos a un riesgo mayor ante la infección provocada por el coronavirus.

Cuando un determinado colectivo sufre una amenaza y puede poner en marcha recursos, medios, capacidades, para enfrentarla, la posibilidad de que esa amenaza se convierta en un riesgo descontrolado, se reduce e incluso desaparece. Por tanto, no es la gravedad de la amenaza lo que puede desembocar en la pandemia, sino cómo interacciona con comunidades o grupos sociales, incrementando o por el contrario, disminuyendo el riesgo de enfermarse.

El riesgo ${ }^{11}$ es algo que se ha ido construyendo socialmente y en la situación que vivimos hoy, la pandemia ha ido desnudando problemas preexistentes en materia de mala gestión de riesgos y de preparación, predicción y prevención ante ellos. Todos estos aspectos son trabajados habitualmente en temas ambientales desde la Teoría Social del Riesgo (TSR) pero como opinan los investigadores del Grupo de Estudios de Geografía Urbana, de la FFyL de la Universidad de Buenos Aires (UBA), "La pandemia se presta para aplicar conceptos de la TSR y así, vincular el riesgo sanitario con la problemática urbana en términos de Amenaza, Exposición, Vulnerabilidad e Incertidumbre" (Conversatorio Instituto de Geografía, UBA, 19/05/2020). Volvemos sobre esto en el apartado siguiente, para mencionar las vulnerabilidades y riesgo a los que están expuestos los habitantes de los barrios populares o asentamientos informales.

Desde otra perspectiva teórica, el geógrafo brasilero, Rogerio Haesbaerth plantea que en el contexto de cuarentena por la pandemia, se produce la des-territorialización como control o pérdida

11 En las definiciones convencionales de las Naciones Unidas, el riesgo es la "posibilidad de que se produzcan muertes, lesiones o destrucción y daños en bienes en un sistema, una sociedad o una comunidad en un período de tiempo concreto, determinados de forma probabilística como una función de la amenaza, la exposición, la vulnerabilidad y la capacidad". Es, por tanto, un concepto mucho más útil y poderoso que el de vulnerabilidad para referirse a situaciones, como las que estamos viviendo, en las que lo relevante no es solo la condición de partida de ciertos grupos (su mayor o menor vulnerabilidad o capacidad), sino el cómo esta condición puede desembocar en riesgos cuando se expone a la amenaza del virus. 
Año 16, Vol. 11, número 21, agosto-diciembre

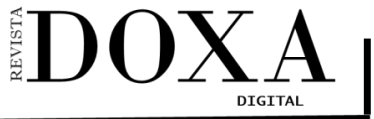

pISSN: 2395-8758 elSSN: 2594-2786
Sección: Ciencias Sociales

DOI: $10.52191 /$ rdojs.2021.201

pág.: 52-71
Beatriz Ensabella

Una mirada socioambiental ...

frente a las amenazas sobre nuestros espacios, que son, al mismo tiempo, espacios funcionales y vividos (el espacio de la casa pasa a ser un espacio vivido por excelencia). Enfatiza el sentido social del término des-territorialización: pérdida de control impuesta a tanta gente por su condición precaria, des-territorialización como sinónimo de precarización territorial. Una dimensión muy importante de esa precariedad es el control de las condiciones básicas de salud para la sobrevivencia de estos grupos y junto con eso lo que se podría denominar el territorio del cuidado o el cuidado del territorio.

En fin, interesantes reflexiones para seguir profundizando, ya que estas categorías pasan a tener protagonismo para explicas el origen, la difusión y los efectos presentes y futuros de la pandemia, donde los geógrafxs y los científicos en general, tienen un papel destacando desde su labor, aportando información para el cuidado de la salud pública ${ }^{12}$.

\section{Algunas referencias sobre la pandemia en Argentina}

Argentina, al igual que los países del mundo, tomó las recomendaciones de la OMS, respecto de implementar medidas de confinamiento, aislamiento social preventivo obligatorio (ASPO) y se implementó desde la 0 hora del 20 de marzo de 2020. Con el transcurso de los meses, se fueron otorgando diversas flexibilizaciones y en este momento, se está procediendo al plan de vacunación contra el Covid 19, aunque la inmunidad de rebaño llegará para la segunda mitad del año en curso, según estimaciones del Ministerio de Salud de la Nación.

Analicemos ahora, el comportamiento espacial del virus en la escala nacional. Con el objetivo de controlar la difusión de los contagios y prevenir la expansión del coronavirus, se movilizó a los científicos (infectólogos, virólogos, médicos sanitaristas, etc) quienes a través de las instituciones específicas, y en colaboración con las universidades e investigadores del CONICET, se fue produciendo la base de datos y la cartografía útil para la toma de decisiones.

Argentina, como otros países sudamericanos ${ }^{13}$, registró una concentración de casos y una mayor incidencia de contagios, en la ciudad de Bs As y su Área Metropolitana (AMBA) y en menor medida, en las capitales de provincias. Relacionado con esto, un comentario de la socióloga urbana Natalia Cosacov abona la idea de esa concentración, como proceso socioespacial histórico de la

12 La generación de cartografía específica, las herramientas disponibles a través de los SIG que permiten el análisis espacial, constituyen información valiosa para poder comunicar el estado de situación, tomar medidas al respecto.

13 Para ampliar el tema, se puede consultar el Conversatorio virtual organizado por el Colegio de Geógrafos de Valparaíso, titulado: "Aportes de la Geografía al análisis de la expansión del Covid 19", 14 de agosto de 2020. https:// www.facebook.com/watch/live/?v=982927395480811\&ref=watch permalink 
Año 16, Vol. 11, número 21, agosto-diciembre

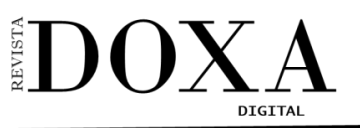

pISSN: 2395-8758 eISSN: 2594-2786
Sección: Ciencias Sociales

DOI: $10.52191 /$ rdojs.2021.201

pág.: 52-71
Beatriz Ensabella

Una mirada socioambiental ...

\section{Argentina}

El hecho de que la pandemia en Argentina se concentre en el AMBA, muestra que el territorio es el resultado de procesos sociales, pero también es productor de dinámicas sociales, que tienen un papel activo en el curso que toman los procesos. Milton Santos llamó "inercia dinámica" a esta tendencia del espacio a reproducir la estructura glotal que le dio origen. El territorio argentino y su grado de concentración y centralización en el AMBA es un producto social e histórico que hoy se impone como mediación ineludible, imprimiéndole a la pandemia, una orientación particular y jsi todo circula en el AMBA, si allí todo se concentra, por qué no lo haría el virus? Es el centralismo como hecho socio-espacial que se (nos) impone. Podremos llegar a construir un país más federal? (10 de julio, FB)

En suma, la pandemia, como propuso en un artículo Ramonet, puede ser pensada como un hecho social total en tanto viene a conmover todas las dimensiones de la vida social, entre ellas el espacio y la espacialidad. El mapa a continuación, expresa la concentración de la que venimos hablando (imágenes ilustrativas extraídas de internet).

Figura 1: Distribución de casos confirmados de Covid 19 por departamentos provinciales, República Argentina, agosto 2020

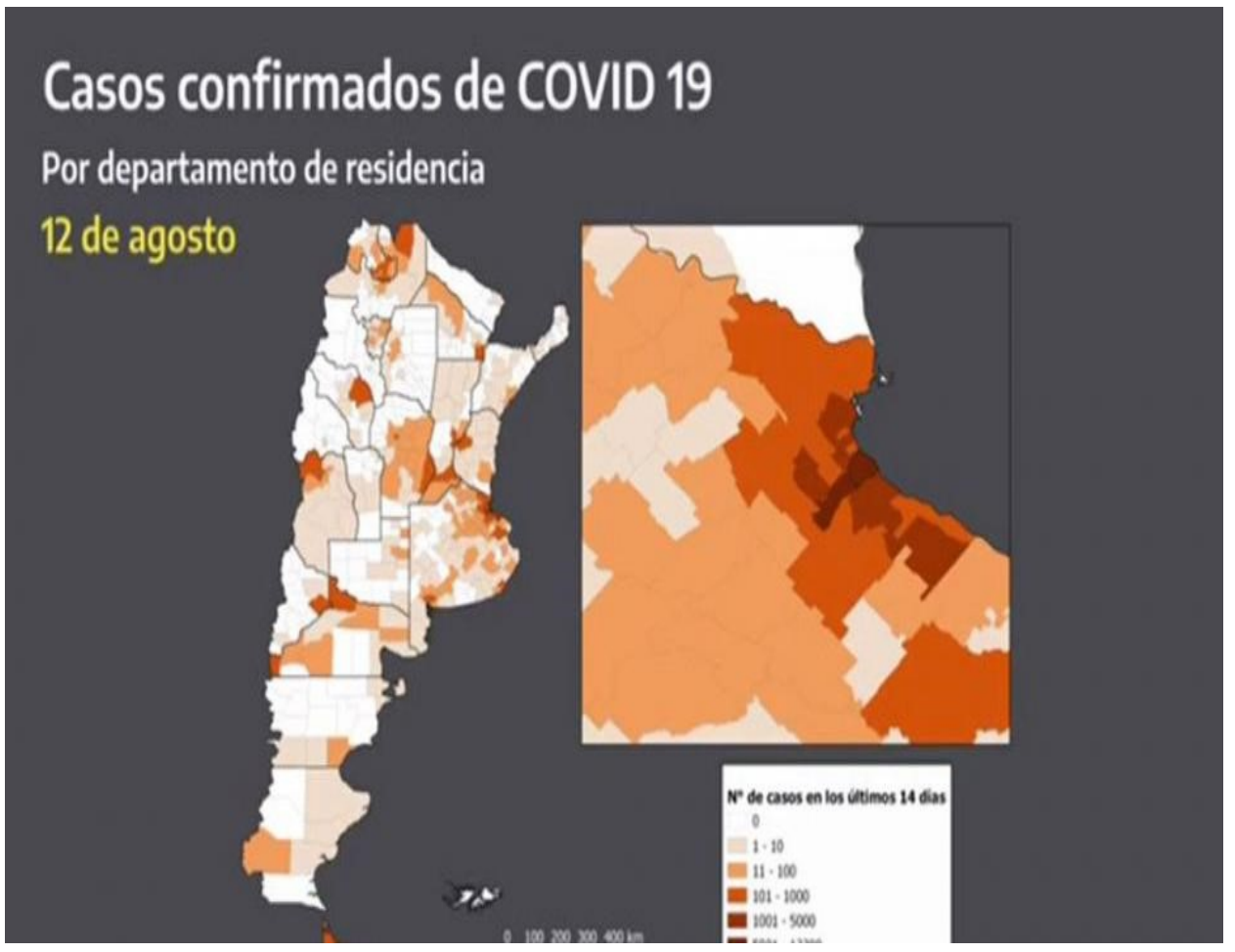

Fuente: Dirección Nacional de Epidemiología e información estratégica de la República Argentina. 
Año 16, Vol. 11, número 21, agosto-diciembre

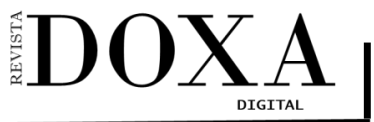

PISSN: 2395-8758 eISSN: 2594-2786
Sección: Ciencias Sociales

DOI: $10.52191 /$ rdojs.2021.201

pág.: 52-71
Beatriz Ensabella

Una mirada socioambiental ...

Usando los cinco principios del análisis espacial geográfico:

- Localización espacial: casos en estudio, contagiados, recuperados día por día: se elaboran tablas, tasas de contagios y se espacializa por provincias y por departamentos.

- Distribución espacial: mapas temáticos que muestran patrones de distribución.

- Asociación de variables: densidad demográfica, población por edades, población de riesgo. Se elabora un Índice de riesgo: con indicadores específicos (clasificación socio-económica de hogares) y esto permite construcción de mapas de vulnerabilidad.

- Interacción: circulación de bienes y de personas, movilidad territorial, flujos (cantidad y frecuencia).

- Evolución espacial y temporal: técnica de isopletas, interpolación de datos, elaboración de curvas.

Figura 2: Gráficos sobre cantidad de casos activos, casos recuperadfos y fallecidos totales por provincias, Argentina, mayo 2020

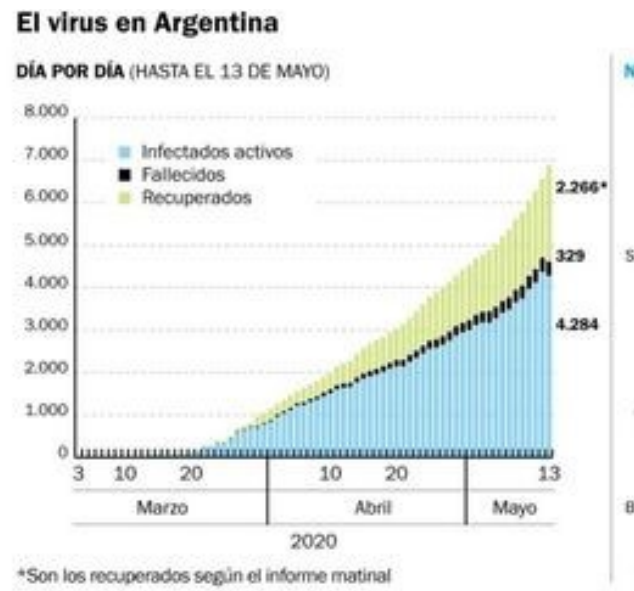

* Son los recuperados segìn el informe matinal

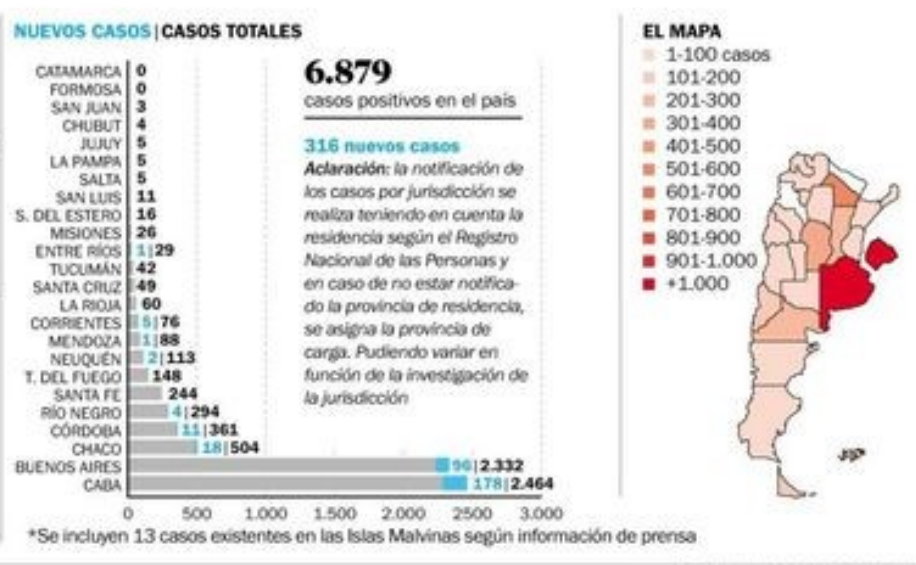

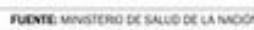

Fuente: Ministerio de Salud de la Nación

La geografía, a través del análisis espacial, aporta insumos para la toma de decisiones y en este sentido, con la propagación del coronavirus, se ha revalorizado la vertiente científica de orientación médico-sanitarista, que con sus datos, mapas y trabajo multidisciplinario, está siendo tan efectiva en la situación de pandemia.

Avanzando sobre las causas de la enfermedad del Covid 19 desde una escala macro aparece, 
Año 16, Vol. 11, número 21, agosto-diciembre

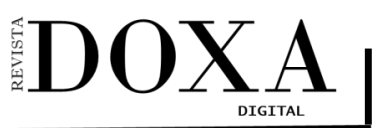

pISSN: 2395-8758 elSSN: 2594-2786
Sección: Ciencias Sociales

DOI: 10.52191/rdojs.2021.201
Beatriz Ensabella

Una mirada socioambiental ...

pág.: 52-71

el cambio climático, las deforestación, el tráfico de animales, el capitalismo financiero, la globalización. Cuando se examina la cantidad de casos, los contagios a escala micro, aparecen las vulnerabilidades de la vida en los barrios populares ${ }^{14}$, con hacinamiento, ausencia de acceso a servicios básicos. Y estas cuestiones son las que estudian las ciencias sociales y son las que se debería tener en cuenta para generar políticas públicas acordes a las realidades temporales y microespaciales.

Soledad Santini, Directora de endemo-epidemias del Instituto Malbrán de Buenos Aires, sostiene que "no es azar que los casos exploten en los espacios más vulnerables" (Entrevista Diario Tiempo Argentino, 14 de junio de 2020). No es ignorado que en el contexto de los barrios populares se presentan problemas que deben ser encarados con urgencia ${ }^{15}$, entre otros:

- Hacinamiento

- Violencia institucional (la presencia de las fuerzas de seguridad y la militarización de los barrios populares se intensificó durante las primeras semanas del ASPO y lo hizo aún más ante la detección de casos positivos

- Violencia de género (agravamiento durante el aislamiento obligatorio) - Exclusión educativa (niños y adolescentes que ahora no tienen acceso a educación, ni presencial ni virtual)

- Desprotección económica y crisis alimentaria (los comedores comunitarios, los merenderos pasaron a estar superpoblados dado el incremento exponencial de la demanda.

- Carencia de adecuados servicios de salud y ausencia de testeos a lo que se suma el ocultamiento de casos de infección.

Acordamos con la Dra. Santini cuando sostiene: "La organización del espacio es una política sanitaria: si el lugar tiene espacios verdes, si hay distancia entre las casas, o las formas de llegar al trabajo, si es estresante, densa, todo eso repercute en la salud". La organización espacial de la Ar-

\footnotetext{
14 Si bien la denominación de barrios populares es una categorización debatida en la bibliografía, creemos que da cuenta de un proceso iniciado por los movimientos sociales de reconocimiento de estos espacios habitados por sectores populares de las distintas ciudades de nuestro país. Sostenemos que invierte la carga negativa que implica hablar de informalidad (en cuanto a que no cumplen con normativa urbanística y también por la marginalidad que sufren sus habitantes).

15 A nivel nacional existe una ley que es el "Régimen de regularización dominial para la integración socio-urbana" de aquellos barrios identificados en el Registro Nacional de Barrios Populares en Proceso de Integración Urbana (RENABAP), que implica y compromete una serie de intervenciones públicas para aquellos espacios caracterizados previamente como asentamientos o urbanizaciones irregulares o informales.
} 
Año 16, Vol. 11, número 21, agosto-diciembre

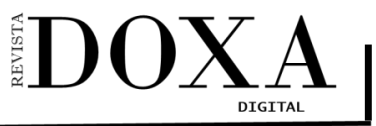

pISSN: 2395-8758 elSSN: 2594-2786
Sección: Ciencias Sociales

DOI: $10.52191 /$ rdojs.2021.201

pág.: 52-71
Beatriz Ensabella

Una mirada socioambiental ...

gentina, es como la cabeza de Goliat, todo confluye en Buenoss Aires y eso nos perjudica, incluso para la propagación de enfermedades. La pandemia trajo a debate la importancia de tener ciudades con menos densidad, más homogéneas y descentralizadas, transportes limpios, menos atestados, y una matriz económica y productiva redistribuida en todo el territorio nacional. Por eso es urgente pensar políticas estratégicas a mediano y largo plazo, para organizar las redes de comercio y transporte y la urbanización. "Se trata de una planificación estratégica para los espacios donde se escuchen todas las voces, principalmente la de los territorios, que sin duda, tienen voz propia" (Entrevista Soledad Santini, 14 de junio de 2020).

El surgimiento de nuevas deseconomías de aglomeración y la preponderancia de fuerzas centrífugas como resultado de la pandemia significan un fuerte dilema para los planteos centrales del urbanismo en la última década. Claramente en los países centrales pero también en América Latina y en Argentina, desde el urbanismo se viene propugnando con fuerza el paradigma de la ciudad compacta, como alternativa necesaria frente a los males de la dispersión urbana. La idea de promover ciudades compactas también se observa en los planteos de la ONU a través de los documentos de Hábitat III (2016) y en estudios en Argentina sobre la expansión de los grandes aglomerados urbanos (Centro de Implementación de Políticas Públicas para la Equidad y el Crecimiento - CIPPEC, 2018). En el marco de estos paradigmas se viene remarcando la importancia de la densidad urbana, tanto en términos morfológicos como políticos, por su capacidad de promover el intercambio social y formas de ciudadanía más progresistas, que superen el aislamiento. También se viene dando una fuerte revalorización del transporte público frente a los impactos negativos de la movilidad privada individual. ¿Cómo reaccionará este paradigma urbanístico, que parece tener características positivas, frente al contexto de pandemia? ¿Mantendrá sus planteos centrales en torno a la densidad y la compacidad y tratará de adecuarlos o, al contrario, perderá fuerza y sustento y retrocederá hacia planteos anteriores?

Más allá de estas cuestiones que habrá que analizar con horizontes temporales más amplios, no podemos dejar de mencionar las distintas iniciativas (quizás viejos anhelos de algunas generaciones de geógrafos de todos los tiempos) para corregir los desequilibrios espaciales y la excesiva concentración de la población, el trabajo, el poder en Capital Federal. Sobre este tema el Magister Jorge Blanco expuso en la 6ta Conferencia "Federalismo, regiones y ciudades pospandemia" orga- 
Año 16, Vol. 11, número 21, agosto-diciembre

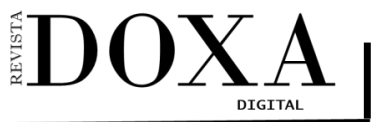

pISSN: 2395-8758 elSSN: 2594-2786
Sección: Ciencias Sociales

DOI: $10.52191 /$ rdojs.2021.201

pág.: 52-71
Beatriz Ensabella

Una mirada socioambiental ...

nizada por Instituto de Capacitación Parlamentaria, el 25 de agosto de 2020. Fundándose en el Plan Estratégico Territorial ${ }^{16}$ y diversos proyectos de ordenamiento territorial, observa la importancia de incidir desde algunas políticas, en el desequilibrio y la concentración ${ }^{17}$.

\section{Reflexiones Finales}

La irrupción del coronavirus, modificó nuestras existencias a nivel planetario y afectó las relaciones interpersonales, de la ciudadanía con sus gobiernos y también las relaciones internacionales. Ni mencionar los efectos económicos a todo nivel.

Este escenario, que se extendió más de lo que se suponía, sumado a la incertidumbre en el futuro, movilizó a pensadores y científicos de las más diversas disciplinas y en este ensayo hemos destacado, algunas miradas y aportes al contexto pandémico desde la geografía, disciplina del campo de las ciencias sociales.

Es cierto que para controlar la enfermedad y continuar con nuestras vidas, hay que avanzar con los estudios científicos. Pero no sólo es clave la ciencia, sino también la solidaridad. Valoramos el conocimiento experto que tan útil está siendo en este contexto pero nos abre el desafío hacia el por-venir, en tanto esa validación no vuelva a negar otros registros, otros saberes, otros espacios de diálogo, de conocimiento, y en esto las ciencias sociales, las artes y las humanidades deben tener un lugar central, no sólo para interpretar el fenómeno y sus consecuencias en la salud social y colectiva, sino también en la interpretación de horizontes de existencia para el planeta, las sociedades, los sujetos, en un mediano y largo plazo.

La pandemia Covid-19, si bien inédita en su escala y su inmediatez, no es un hecho aislado. El coronavirus es un asunto grave y ciertamente su propagación es consecuencia del peligro que el virus mismo significa para el cuerpo humano; pero aquí hay cuestiones sociales que merecen abordarse. Para cualquier discusión debe ser clave el evidente colapso de la naturaleza, tal como la ha tratado el sistema capitalista, privatizando los bienes comunes, minimizando los costos y maximizando las ganancias. Eso es algo que tenemos que cambiar y allí es importante relacionar el conocimiento académico y los saberes locales, comunitarios, ancestrales.

16 Las planificaciones espaciales se plantearon a nivel nacional en un ambicioso plan concretado en etapas, el Plan Estratégico Territorial -PET Argentina 2011 y el PET 2016. Se trata en esencia, de una planificación estratégica coordinada por el gobierno nacional, tendiente al despliegue de la inversión pública y el desarrollo territorial.

17 En un artículo de opinión titulado ¿un país desequilibrado? el geógrafo Carlos Reboratti expresa sus objeciones a planes que, poco inciden en corregir esa tendencia a la macrocefalia de Argentina. Sostiene que es una cuestión histórica y parte de nuestra territorialidad a nivel nacional que no es buena ni mala en sí misma, entonces poco pueden hacer los planes tendientes a revertir ese fenómeno (Clarín, 09/08/2020). 
Año 16, Vol. 11, número 21, agosto-diciembre

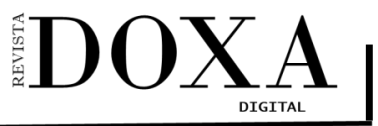

pISSN: 2395-8758 eISSN: 2594-2786
Sección: Ciencias Sociales

DOI: $10.52191 /$ rdojs.2021.201
Beatriz Ensabella

Una mirada socioambiental ...

pág.: 52-71

Es posible observar que la concentración, la deforestación y destrucción de hábitats no son procesos nuevos, pero alcanzan en la actualidad una magnitud que sobrepasa el límite crítico dado que se retroalimenta con otros procesos en marcha en las últimas cuatro décadas como la urbanización acelerada y la hipertrofia en la circulación de flujos que hacen muy dificultoso contener la crisis y la propagación de virus.

Martinez Alier (2000) afirma: "Para disminuir lo ficticio es necesario reestructurar el ámbito político y económico actual hacia un modelo con base en la educación, la conciencia ecológica y la defensa de la identidad cultural. Esta propuesta hoy puede parecer utópica o, incluso, como una historia ya contada, sin embargo, las utopías existen, por una parte, para poder caminar con el firme propósito de vencer las adversidades y, por otra, como fiel reflejo de la inconformidad basada en lo que no se ha hecho".

Hay que tener claro que no se puede generar una salud pública coherente si amplios sectores se encuentran viviendo por debajo de la línea de pobreza y con déficit habitacionales generalizados. Esto también hay que cambiarlo.

Esto aparece como un problema pero también como una oportunidad para revalorizar la escala (sub) local: posibilidad de reafirmar al barrio como lugar de arraigo, lugar de vida y de trabajo, a la población local como sujeto transformador en términos espaciales. Se hace referencia a la posibilidad de fortalecer lo territorial-barrial, los proyectos locales como alternativa. Sin embargo, también cabe discutir los límites de esas posibilidades en el contexto estructural de exclusión.

También se debería pensar en la cuestión del acceso al suelo, a los servicios en general pero particularmente en la educación por falta de conectividad y esto no sólo en los asentamientos populares, sino también en las regiones menos urbanizadas "del interior". En fin, un sinnúmero de problemáticas preexistentes pero que salieron a la luz de forma muy evidente con la pandemia e invita a gobiernos y a la sociedad, a replantear los modos de existencia, sobre todo en relación con la "explotación" de los recursos naturales para la producción. Será necesario cambiar el modelo extractivista, mercantilista y pensar relaciones más equilibradas entre países y a nivel local.

\section{Referencias}

Araujo González, Rafael (2015) Vulnerabilidad y riesgo en salud: ¿conceptos concomitantes? Novedades en población, Vol 11, $\mathrm{N}^{\circ} 21$, ene-jun. La Habana.

Blanco, Jorge (2020) 6ta Conferencia "Federalismo, regiones y ciudades pospandemia" organizada 
Año 16, Vol. 11, número 21, agosto-diciembre

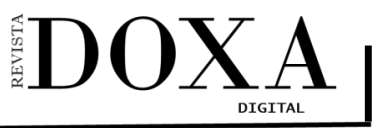
eISSN: 2594-2786
ISSN: 2395-8758
Sección: Ciencias Sociales

DOI: 10.52191/rdojs.2021.201

pág.: 52-71
Beatriz Ensabella

Una mirada socioambiental ...

por Instituto de Capacitación Parlamentaria, 25 de agosto de 2020. https://www.youtube.com/ watch?v=36BzileY H0\&ab channel=InstitutodeCapacitaci\%C3\%B3nParlamentaria

Carbonetti, A., Rodriguez, M. L. y Rivero, M. D. (2018) Convicciones, saberes y prácticas higiénicas argentinas en la segunda mitad del siglo XIX. Sus condiciones de posibilidad en los estudios de las epidemias de cólera de 1868, 1871 y 1887. Investigación y Ensayos $N^{\circ} 66$. Academia Nacional de Historia de Argentina. Pp 75-110.

Cosacov, Natalia (2020, 9 de julio).Facebook, consultado el 23 de marzo de 2021. https:// www.facebook.com/naticosacov

Epstein, Paul, 1997: Climate, ecology, and human health. Consequences Volume 3, Number 1, 1997, 1.

Entrevista de Karina Bidaseca para Clacso Tv, del 30 de setiembre de 2019. https://www.clacso.org/ la-ecologia-politica-segun-enrique-leff/

Entrevista a Soledad Santini. Diario Tiempo Argentino, 14 de junio de 2020.

https://www.tiempoar.com.ar/nota/no-es-azar-que-los-casos-exploten-en-los-espacios-masvulnerables

Grupo de estudios de geografía urbana, Instituto de Geografía "Romualdo Ardisone". FFyL-UBA, Conversatorio virtual, 19 de mayo de 2020. https://www.youtube.com/watch? v=z7b9TUYdAao\&t=1s\&ab channel=FILOUBA

Hidalgo, Rodrigo et al (2020) Editorial. Revista de Geografía Norte Grande, 76: 5-8.

Martínez Alier, Joan (2000) Deuda ecológica. Economía Política. Espacios Nº 19 (2). Pp: 105-110. Montoya DM, Olaya FM, Carvajal YV, Echavarría SJ, Arango AC, Domínguez CM, Marín HA, Noreña C, Higuita CA, Saldarriaga JF, Martínez E, Rojas CA. (2009). Epidemiología y la relación salud-ambiente: reflexiones sobre el cambio ambiental, desarrollo sustentable y salud poblacional. Revista de la Facultad Nacional de Salud Pública N²7(2). Pp: 211-217.

Moore, Jason (2020) El capitalismo en la trama de la vida. Ecología y acumulación de capital. Ed Traficante de sueños.

(2013) El auge de la economía mundo capitalista. Las fronteras mercantiles en el auge y decadencia de la apropiación máxima. Laberinto $N^{\circ} 38$. Pp: 9-25.

Prashad, Vijay (2020). Alerta roja 7: Hechos fundamentales sobre el nuevo coronavirus y la COVID- 
Año 16, Vol. 11, número 21, agosto-diciembre

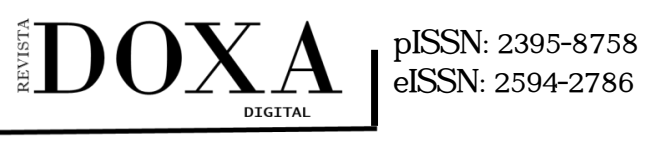

Beatriz Ensabella

Una mirada socioambiental ...

DOI: $10.52191 /$ rdojs.2021.201

pág.: 52-71

19 Boletín Instituto Tricontinental No 22, 29 de mayo de 2020. https://mail.google.com/mail/ u/0/?tab=rm\&ogbl\#search/boletin+instituto+tricontinental/

FMfcgxwHNgWwJmhwxJMZbvsKLjpcpGSJ

Reboratti, Carlos para Clarín “¿un país desequilibrado?” 9 de agosto de 2020. Recuperado de https://www.clarin.com/opinion/pais-desequilibrado $0 \mathrm{kXHbzaCpN.html}$

Robinson, W. (2013) Una teoría sobre el capitalismo global de 2013. Siglo XXI.

Sandoval, Rafael [Coord. y Edit.] (2018) Cuaderno 2. Problemas y desafíos de la formación en la metodología de la investigación. Colección Cuadernos de Metodología y Pensamiento Crítico. Grietas editores. 